\title{
Vestígios da criação do primeiro curso de formação de professores de Matemática no Alto Paranaíba, Minas Gerais: um olhar a partir da Revista Documenta
}

\author{
Traces of the creation of the first mathematics professor education course \\ in Alto Paranaíba, Minas Gerais: a look from the Documenta Magazine
}

\author{
Jessiene Adriano de Queluz $\left.\right|^{1}$ \\ Douglas Marin ${ }^{2}$
}

\begin{abstract}
Resumo. Nesse artigo apresentamos resultados iniciais de um projeto em desenvolvimento cujo objetivo é mapear movimentos da criação dos primeiros cursos que formavam professores de Matemática na região do Alto Paranaíba, Minas Gerais. Como fonte principal, temos os pedidos de criação, conversão e/ou reconhecimento de cursos que formavam professores de Matemática, de instituições públicas federais ou privadas, publicados na Revista Documenta - publicação mensal do Conselho Federal de Educação, no entanto, ressaltamos que outras fontes também foram usadas. As inspirações teórico-metodológicas se baseiam na linha/projeto Mapeamento da formação e atuação de professores de Matemática no Brasil, do grupo de pesquisa Grupo História Oral e Educação Matemática, Ghoem. Para esse texto trouxemos resultados do primeiro curso que ocorreu nessa região, em especial na cidade de Patos de Minas. Entre eles, imprimimos uma discussão que abrange o currículo do primeiro curso de formação de professores de Matemática, a listagem dos primeiros professores, indícios da criação da primeira faculdade privada e de outros cursos de formação de professores, do movimento de ensino superior nessa cidade e evidências do auxílio para a criação desse movimento da Igreja Católica. Apontamos que esse estudo é assumidamente historiográfico e se inscreve no campo da História da Educação Brasileira, mais especificamente na História da Educação Matemática no Brasil.
\end{abstract}

\footnotetext{
${ }^{1}$ Faculdade de Matemática, Universidade Federal de Uberlândia, jessienequeluz@gmail.com

${ }^{2}$ Faculdade de Matemática, Universidade Federal de Uberlândia, douglasmarin@ufu.br
} 
Vestígios da criação do primeiro curso de formação de professores...

Palavras-chave. Formação de professores de matemática. Revista Documenta. História da educação matemática.

\begin{abstract}
In this article we present initial results of a project under development whose objective is to map movements for the creation of the first courses that trained mathematics teachers in the Alto Paranaíba region, Minas Gerais. As the main source, we have requests for the creation, conversion and/or recognition of courses that trained mathematics teachers, from federal or private public institutions, published in Documenta magazine - monthly publication of the Federal Council of Education, however, we emphasize that other sources were also used. Theoretical-methodological inspirations are based on the line/project Mapping the training and performance of mathematics teachers in Brazil, from the research group Grupo História Oral e Educação Educação, Ghoem. For this text, we brought results from the first course that took place in this region, especially in the city of Patos de Minas. Among them, we printed a discussion covering the curriculum of the first mathematics teacher training course, the list of the first teachers, evidence of the creation of the first private faculty and other teacher training courses, of the higher education movement in that city and evidence of aid to the creation of this Catholic Church movement. We point out that this study is admittedly historiographic and falls within the field of the History of Brazilian Education, more specifically in the History of Mathematical Education in Brazil.
\end{abstract}

Keywords. Professor education process in higher education. Documenta magazine. History of mathematics education.

\title{
1 Introduçãa
}

Essa pesquisa que ora apresentamos, congrega um estudo que tem como objetivo mapear os movimentos de criação dos primeiros cursos que formavam professores de Matemática na região do Alto Paranaíba, Minas Gerais. Para esse texto, trouxemos uma síntese dos resultados iniciais do primeiro curso que ocorreu nessa região, em especial na cidade de Patos de Minas.

Como fonte principal, temos os pedidos de criação, conversão e/ou reconhecimento de cursos que formavam professores de Matemática, de instituições públicas federais ou privadas, publicados na Revista Documenta [10] - publicação mensal do Conselho Federal de Educação (CFE).

Iniciada em 1962 com edições mensais, a "Documenta é a revista oficial do antigo Conselho Federal de Educação e do atual Conselho Nacional de Educação (CNE). A 
publicação do seu primeiro número coincide com a instalação do CFE: março de 1962" (ROTHEN [26], 2004, p. 264).

A Documenta contém resoluções e pareceres do referido Conselho sobre criação, estruturação, reconhecimentos e extinção de instituições de ensino e cursos, além de alguns textos mais gerais sobre temas educacionais. Ela possui uma característica bem particular, por não ser uma revista acadêmico científica e nem uma reprodução de publicações do Diário Oficial, mas por apresentar características de ambos. Ela é dividida em seções e apresentam diversos temas, assim distribuída como notas, pareceres, indicações, estudos especiais, estatutos, regimentos, autorizações, reconhecimento e outros pronunciamentos (DOCUMENTA $\mathrm{N}^{\circ} 10$ [11], 1962).

Mas, qual era o teor dessas seções? Pode ser que o nosso leitor possa se perguntar sobre isso. Para responder essa questão, localizamos na Revista Documenta $n^{\circ} 135$ [14], de 1972, o significado de como eram tratados pela revista os pareceres.

(...) são proposições em que as Câmaras e as comissões se pronunciam sobre a matéria a elas submetidas. As indicações são de iniciativas dos próprios conselheiros e, em muitos casos, vêm acompanhadas de propostas de resoluções. As resoluções aprovadas pelo plenário do Conselho são atos de caráter normativo, sendo de inciativa dos próprios conselheiros ou solicitados pelas Câmaras ou pelo plenário a um conselheiro ou uma comissão constituída de membros do Conselho (DOCUMENTA No 135 [14], 1972, p. 318).

Nota-se pela citação que há um rigor entre as tarefas referente ao CFE no que tange aos pareceres e as publicações da Revista Documenta, ela expõe todo esse trabalho realizado no Conselho.

Nesse sentido, entendemos que esta publicação tem sido de grande valia para pesquisadores, em particular àqueles que pesquisam na linha História da Educação Matemática e tem se mostrado como uma importante fonte para as pesquisas nessa área (GOMES [19], 2019).

É importante frisar que este estudo se inspirou nos aspectos teórico-metodológicos da linha/projeto Mapeamento de Formação de Professores que Ensinam Matemática no Brasil, do Grupo História Oral e Educação Matemática, Ghoem, do qual fazemos parte.

Entendemos que essa linha/projeto é uma configuração aberta, que visa registros das condições em que ocorreram a formação e atuação de professores que ensinavam/ensinam Matemática e da criação de cursos de formação superior para a formação docente no campo da Matemática, abordando a diversidade geográfica, institucional e temporal, e é nessa perspectiva em que esse estudo se aproxima.

A preocupação desta linha/pesquisa com a formação de professores é latente, mas, também, voltam seus olhares para as práticas no fazer pedagógico nas diversas modalidades de ensino, na institucionalização de cursos que formavam professores de Matemática, 
Vestígios da criação do primeiro curso de formação de professores...

na formação da identidade de grupos de pesquisa, no traçado do perfil de professores e alunos de distintas regiões, nas motivações políticas, administrativas e sociais, entre outros vieses (BARALDI [2], 2018; GARNICA [16], 2018).

A partir do exposto apontamos que esse estudo é assumidamente historiográfico e se inscreve no campo da História da Educação Brasileira, mais especificamente na História da Educação Matemática no Brasil.

\title{
2 História, História da Educação Matemática: algumas compreensões
}

Ao questionar alguém sobre o que seria História, poderíamos receber algumas respostas previsíveis como, por exemplo: "uma forma de estudar o passado", ou "a ciência que investiga o passado da humanidade e o seu processo de evolução".

Apoiamos em Albuquerque Jr. quando diz que

\begin{abstract}
a História seria movimento, seria ação criativa, invenção constante de novos lances, mesmo que seus sujeitos estejam limitados por regras, por normas, tenham que obedecer a regulamentos. A História é possível porque os homens, mesmo limitados por um dado contexto, por um conjunto de regras e prescrições, mesmo atuando em um espaço e um tempo delimitado, são capazes de driblar a potência do mesmo e a imposição de repetição e criar o diferente, a novidade, de produzirem a surpresa e o inesperado. A História, como jogo, faz-se de risco e habilidade, de variação e mudança, de limite e invenção, de regras imanentes e de restrições voluntárias (ALBUQUERQUE JR. [1], 2011, p. 173).
\end{abstract}

Ao ver a História como uma forma de expressar algo do passado a partir do presente, compreendido por meio de indícios que podem ser encontrados em fontes de várias naturezas (orais, escritas, arquitetônicas etc) nos possibilita inventar versões plausíveis de um passado. Como se fosse uma "viagem que conecta e mistura tempos e espaços, que interpenetra coisas e representações, realidade e discurso, razões e sentimentos, matéria e sonho, desejo e obrigação, liberdade e determinação" (ALBUQUERQUE JR. [1], 2011, p.30).

Garnica e Souza [17] (2012, p. 21), com base em Marc Bloch, têm defendido a concepção de que a História, de forma geral, é "uma ciência dos homens no tempo e espaço. Mas como não se vive só, e sim, em comunidade, poderíamos enunciar a concepção de História [...] como: a História é o estudo dos homens vivendo em comunidade no tempo".

A História é, então, uma construção sem relação ao mundo em si, mais especificamente: 


\begin{abstract}
A História é um discurso cambiante e problemático, tendo como pretexto um aspecto do mundo, o passado, que é produzido por um grupo de trabalhadores cuja cabeça está no presente (e que, em nossa cultura, são na imensa maioria trabalhadores assalariados), que tocam seu ofício de maneiras reconhecíveis uns para os outros (maneiras que estão posicionadas em termos epistemológicos, metodológicos, ideológicos e práticos) e cujos produtos, uma vez colocados em circulação, vêem-se sujeitos a uma série de usos e abusos que são teoricamente infinitos, mas que na realidade compreendem a uma gama de bases de poder que existe naquele determinado momento e que estruturam e distribuem ao longo de um espectro do tipo dominantes/ marginais os significados das histórias produzidas (JENKINS [20], 2005, p. 52).
\end{abstract}

Assim, ancorados nesses autores estamos entendendo que a História é um diálogo contínuo, permanente, entre passado e presente. O passado faz parte do presente, sendo o presente um questionador do passado, em outras palavras, a História é uma invenção do presente, com ligações e rastros enfincados no passado.

Nesse sentido, os acontecimentos do passado podem ter diferentes significados, dependendo da forma em que são registrados, interpretados e transmitidos. Para isso, elegemos o trabalho a partir de acontecimentos, podendo, com isso, apresentar-se como uma interessante intervenção para a produção de conhecimento, proporcionando de que vivenciamos e registramos, assim, "alguma" História e não "a” História com um significado unívoco, global e generalizante.

Em vista disso passamos a perceber melhor um novo campo que se abre, chamado de História da Educação Matemática. Ele visa a compreender as alterações e permanências nas práticas relativas ao ensino e à aprendizagem de Matemática; a estudar como as comunidades se organizavam no que diz respeito à necessidade de produzir, usar e compartilhar conhecimentos matemáticos e como, afinal de contas, as práticas do passado podem - se é que podem - nos ajudar a compreender, projetar, propor e avaliar as práticas do presente (GARNICA e SOUZA [17], 2012).

Em síntese, para finalizar, por meio da História da Educação Matemática, pode-se compreender instâncias de formação, instituições formadoras, o atendimento ou subversão de legislações. Ela também nos ajuda a entender os modos como as comunidades se organizavam para produzir conhecimentos matemáticos. E, é nesse campo que esta pesquisa está ancorada.

\title{
3 Metodologia
}

Como já dissemos, no presente texto, apresentamos vestígios da criação do primeiro curso de formação de professores de Matemática, na região do Alto Paranaíba, em especial em Patos de Minas. 
Essa cidade está localizada na mesorregião do Triângulo Mineiro e Alto Paranaíba e pertence ao estado de Minas Gerais. Para auxiliar na visualização geográfica dessa localidade, apresentamos a Figura 1. Ao fundo temos o mapa do Brasil, nele ressaltamos em vermelho o estado de Minas Gerais]. Já o mapa em maior destaque, sobressai o estado mineiro com as suas mesorregiões, nele colorimos em vermelho a cidade de Patos de Minas, contornamos em verde a microrregião do Alto Paranaíba e circulamos em amarelo a mesorregião Triângulo Mineiro e Alto Paranaíba.

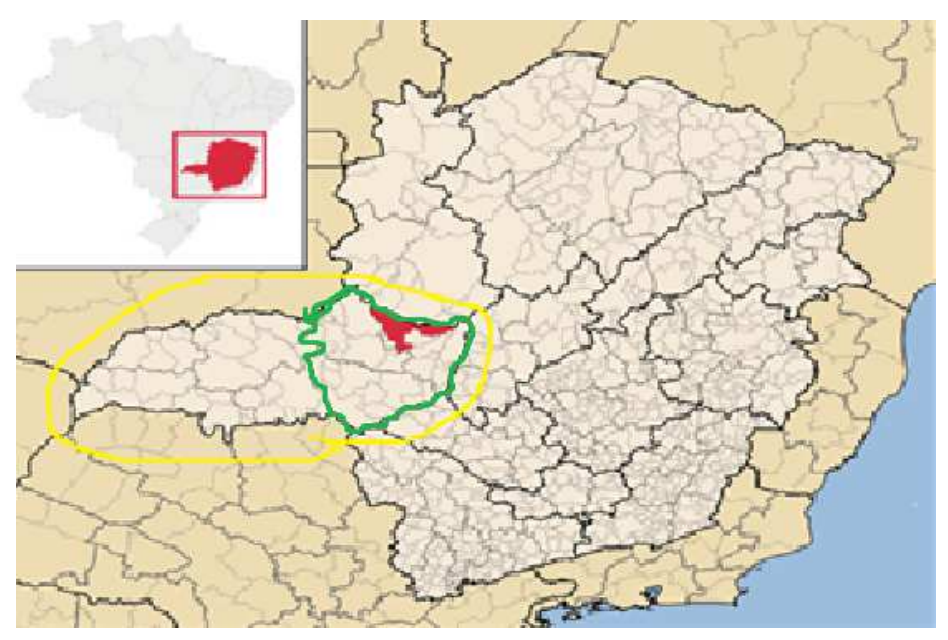

Figura 1: Localização de Patos de Minas.

Fonte: Wikipedia [24].

Para a elaboração dos resultados apresentados, a partir das edições da Revista Documenta que foram publicadas nos anos de 1962 até 1980 nos serviu de fonte. No entanto, por se tratar de um trabalho historiográfico outras fontes disponíveis também nos apoiaram a entender o movimento de criação do primeiro curso de formação de professores de Matemática em Patos de Minas.

O levantamento de dados foi realizado junto ao acervo da Revista Documenta que está localizado na biblioteca da Universidade Federal de Uberlândia, Campus Santa Mônica. Em seu acervo conta com 530 edições da Revista Documenta, tendo sua última publicação física em 2005. Em sua pesquisa Queluz [25] (2020) nos assevera que a partir de 2005

\footnotetext{
${ }^{1}$ A partir de 1960, surge a delimitação do país por microrregiões e, em 1970, são criadas as mesorregiões, fixando, assim, as Unidades da Federação. O estado de Minas Gerais foi dividido em doze mesorregiões, sendo elas, Vale do Rio Doce, Vale do Mucuri, Jequitinhonha, Central Mineira, Metropolitana de Belo Horizonte, Oeste de Minas, Zona da Mata, Campo das Vertentes, Sul/Sudoeste de Minas, Norte de Minas, Noroeste de Minas e Triângulo Mineiro e Alto Paranaíba (MARIN [21], 2019).
} 
teríamos a versão online dessa publicação, no entanto, não conseguimos localizar.

Enfim, todas as informações foram digitalizadas e arquivadas, depois foi elaborado um estudo sistemático tomando por base o uso de tabelas para o auxílio da compreensão e análise dos dados. Sobre isso que trata na sequência do texto.

\section{Indícios da criação do primeiro curso de formação de professores de Matemática em Patos de Minas}

Ao estudarmos sobre a criação do curso de formação de professores de Matemática em Patos de Minas, percebemos que ela se confunde com a instalação do ensino superior nessa cidade.

Segundo Boaventura [3] (2008) existia na cidade um anseio para a criação da primeira faculdade, no entanto, a comunidade local tinha interesse em fundar uma Faculdade de Medicina, mas devido aos custos e a necessidade de habilitar os professores da época, optou-se pela criação de uma faculdade para formar professores.

O primeiro passo foi dado em 27 de maio de 1968 quando o Governador do Estado de Minas Gerais, Israel Pinheiro da Silva, anunciaria, em visita à cidade, a criação da Fundação Universitária de Patos de Minas, sancionada através da Lei no 4.776/68.

Boaventura [3] (2008) nos assevera que embora a Fundação tenha sido instituída em 1968, só em 1970 o Conselho Estadual de Educação aprovou o parecer nº19/70, de 17/03/1970. O Presidente Emílio Garrastazu Médici, através do decreto no 66.443, de 14 de abril de 1970, autoriza o funcionamento da Faculdade de Filosofia, Ciências e Letras de Patos de Minas (FAFIPA), com os cursos de História, Letras, Pedagogia, Ciências Biológicas e Matemática.

Essa autora nos salienta que à época, sem um prédio próprio, a Faculdade funcionou nas instalações dos colégios Marista, Nossa Senhora das Graças e Fonseca Rodrigues. Não podemos deixar de observar que o Colégio Marista era mantido pelos padres da Congregação Marista, o Colégio Nossa Senhora das Graças pelas irmãs da Congregação Sacramentinas de Nossa Senhora e o Colégio Fonseca Rodrigues era laico. Ela ainda ratifica que a estrutura física oferecida por esses colégios era boa e suficiente para atender a demanda que os cursos da FAFIPA necessitavam para o funcionamento.

Em 1974, atendendo alguns pareceres federais que exigiam das fundações uma nomenclatura compatível com as condições a que elas se propunham, pela Lei ${ }^{0} 6.183$ de novembro de 1973, e pelo decreto $\mathrm{n}^{\mathrm{o}} 16.294$ de 22 de maio de 1974, ambos assinados pelo então Governador, Rondon Pacheco, a denominação passou a Fundação Educacional de Patos de Minas. A questão é que a Fundação, então criada, não possuía estrutura de 
Vestígios da criação do primeiro curso de formação de professores...

universidade, apenas de uma Fundação mantenedora de uma única faculdade.

Como já mencionamos o curso de formação de professores de Matemática obteve sua autorização para funcionar junto com a Instituição ao qual o abrigava com total de 2700 horas, correspondentes a 675 horas anuais "havendo condições adequadas, poderá a Faculdade reduzir ou aumentar o tempo de duração dos cursos, obedecendo as normas da Portaria Ministerial $n^{\circ}$ 159/65 e foi autorizado a funcionar com um total inicial de 50 vagas anuais" (DOCUMENTA No 78 [12], 1971, p. 72), com o seguinte currículo mínimo: disciplinas específicas: Desenho Geométrico e Geometria Descritiva, Fundamentos de Matemática Elementar, Física Geral, Cálculo Diferencial e Integral, Geometria Analítica, Álgebra, Cálculo Numérico e Estatística e, disciplinas pedagógicas: Psicologia da Educação: Adolescência-Aprendizagem, Didática, Estrutura e Funcionamento do ensino de $2^{\circ}$ Grau e Prática de Ensino. (DOCUMENTA No 78 [12], 1971, p. 88).

Ao localizar essas disciplinas do primeiro curso de formação de professores de Matemática da FAFIPA, isso nos fez indagarmos se estava correta a quantidade de disciplinas. Para responder nossa dúvida encontramos em Marin [21] (2019) algumas discussões que abrangiam a estrutura curricular dos cursos de formação de professores em que estudou. Nessa pesquisa, esse autor aponta as disciplinas que se tornaram parte da grade do currículo mínimo, a partir de 1962, para os cursos de Licenciaturas Plenas em Matemática, por meio da Lei de Diretrizes e Bases 4024/61 [5], e pelo Conselho Federal de Educação, no parecer 92/62. Desse modo, o currículo mínimo foi estabelecido pelas seguintes disciplinas, de acordo com a Revista Documenta n 10 [11], 1962, p. 85 e 86:

1. Desenho Geométrico e Geometria Descritiva.

2. Fundamentos de Matemática Elementar.

3. Física Geral.

4. Cálculo Diferencial e Integral.

5. Geometria Analítica.

6. Álgebra.

7. Cálculo Numérico.

8. Matérias pedagógicas de acordo com o Parecer $n^{\circ} 292$.

Como podemos observar, esse curso de Matemática o qual estamos estudando seguiu as indicações da Lei 4024/61 [5] a qual instituiu novas reformulações no cenário educacional em relação ao ensino superior, fomentando o debate sobre a duração dos cursos superiores, que os mesmos deveriam ser de quatro anos (BRASIL [4], 1961).

Em relação às disciplinas pedagógicas, identificamos que o curso de Matemática iniciou com as seguintes disciplinas: Psicologia da Educação com foco em AdolescênciaAprendizagem, Didática, Estrutura e Funcionamento do ensino de $2^{\circ}$ Grau, Estudos de 
Problemas Brasileiros, Introdução Geral a Filosofia e Prática de Ensino sob a forma de estágio supervisionado.

Percebemos que a partir dos estudos de Marin [21] (2019) com o intuito de auxiliar no desenvolvimento dos cursos de Licenciatura em Matemática do Brasil, sendo que 1/8 da carga horária total do curso foi destinada para a formação pedagógica, sendo ela, de acordo com a Revista Documenta ${ }^{\circ} 10$ [11] 1962, p. 99:

1. Psicologia da Educação, Adolescência, Aprendizagem.

2. Elementos de Administração Escolar.

3. Didática.

4. Prática de Ensino, sob forma de estágio supervisionado.

Ao compararmos as informações observamos que mais uma vez o curso de Matemática da FAFIPA seguia as orientações do Conselho Federal de Educação. Contudo, é importante apontar que essa padronização do currículo foi importante pois, possibilitou o trânsito de vários estudantes entre as instituições de ensino superior do país. Em Marin [21] (2019), o autor narra que esse trânsito de estudantes de um curso para outro aconteceu nos primeiros cursos de formação de professores (de Matemática) no Triângulo Mineiro.

Na Revista Documenta ${ }^{\circ} 79$ [13], 1971, p. 178 é apontado que no curso de Matemática as disciplinas do currículo mínimo serão distribuídas nas seguintes séries 2 . $\mathrm{Na} 1^{\mathrm{a}}$ série, Desenho Geométrico e Geometria Descritiva, Fundamentos de Matemática Elementar, Cálculo Diferencial e Integral, Geometria Analítica e Introdução Geral à Filosofia; na $2^{\text {a }}$ série, Desenho Geométrico e Geometria Descritiva, Fundamentos de Matemática Elementar, Cálculo Diferencial e Integral, Geometria Analítica, Física Geral, Álgebra e Psicologia da Educação; na $3^{\mathrm{a}}$ série, Fundamentos de Matemática Elementar, Cálculo Diferencial e Integral, Física Geral, Álgebra, Didática Geral e Estudo de Problemas Brasileiros; e por fim, na $4^{\mathrm{a}}$ série, Física Geral, Álgebra, Cálculo Numérico, Estatística, Prática de Ensino e Estrutura de Funcionamento do Ensino de $2^{\circ}$ Grau.

Ao analisar essas informações, não podemos deixar de considerar que as disciplinas Fundamentos de Matemática Elementar, Cálculo Diferencial e Integral, Física Geral e Álgebra eram ministradas em 3 anos do curso. E, em todos os semestres existiam as disciplinas de cunho pedagógico, no entanto, o que chama a atenção, é o fato de apenas no último ano do curso a presença da disciplina de Estágio Supervisionado, onde os estudantes têm o primeiro contato com a escola, e a carga horária dessa disciplina era de apenas 120 horas.

\footnotetext{
${ }^{2}$ Uma observação, nesta época os anos de estudo eram chamados de séries, talvez por influência da escola básica, atualmente isso é entendido por ano em alguns casos menciona-se semestre (MARIN [21], 2019).
} 
No Quadro 1, notamos a relação dos professores que poderiam ministrar aulas na primeira turma do curso de Matemática.

Quadro 1: Corpo docente inicial do Curso de Matemática.

\begin{tabular}{|l|l|}
\hline Docentes & Disciplinas \\
\hline Antônio Cyrino Sobrinho & $\begin{array}{l}\text { Desenho Geométrico, Geometria Descritiva e } \\
\text { Fundamentos de Matemática Elementar }\end{array}$ \\
\hline Marcos Celso G. Amorim & Calculo Diferencial e Integral, Física Geral \\
\hline Terezinha de Deus Fonseca & $\begin{array}{l}\text { Princípios e Métodos de Adm Escolar, Elem. de Adm } \\
\text { Escolar e Elementar Funcionamento do Ensino do 2 }{ }^{\circ} \text { Grau }\end{array}$ \\
\hline Jaime Fonseca & Cálculo Numérico e Álgebra \\
\hline João Eustáquio de Melo & $\begin{array}{l}\text { Fund. de Matemática Elementar e Matemática Apl. a } \\
\text { Biologia }\end{array}$ \\
\hline Elza Rodrigues Pereira & Calculo Diferencial e Integral e Cálculo Numérico \\
\hline Francisco de Assis Lana & Geometria Analítica e Prática de Ensino \\
\hline Maria dos Reis & Didática e Psicologia da Educação \\
\hline José Gontijo & Psicologia da Educação e História da Educação \\
\hline Jair Teixeira da Cunha & Educação Física \\
\hline José Viçoso Rodrigues & Estudos de Problemas Brasileiros \\
\hline
\end{tabular}

Fonte: Documenta $\mathrm{n}^{\mathrm{o}} 79$ [13], 1971, p.178.

Em Boaventura [3] (2008) encontramos uma nota, nela é mencionado que em dezembro de 1973, temos os primeiros formandos pela FAFIPA, em um total de 176 novos professores, desses são apontados 36 para lecionar Matemática. Contudo, essa mesma autora, relata que apenas em 5 de novembro de 1975 , pelo parecer $n^{0} 4.499 / 75$ pelo Conselho Estadual de Educação de Minas Gerais que o curso foi aprovado. Junto com esse parecer é apresentada a relação de professores e disciplinas, isso podemos ver no Quadro 2.

Quadro 2: Corpo docente aprovado para lecionar no Curso de Matemática.

\begin{tabular}{|l|l|}
\hline Docentes & Disciplinas \\
\hline Venâncio Ferreira & Álgebra e Física \\
\hline Maria Conceição dos Santos & Estrutura e Funcionamento do $1^{\circ}$ e $2^{\circ}$ Graus \\
\hline José de Aguiar & Sociologia Geral \\
\hline Lázaro Ferreira da Cunha & Elementos de Estatística \\
\hline Antônio de Oliveira Mello & Estudos de Problemas Brasileiro e Iniciação Filosófica \\
\hline Antônio Cyrino Sobrinho & $\begin{array}{l}\text { Desenho Geométrico, Geometria Descritiva e } \\
\text { Fundamentos de Matemática Elementar }\end{array}$ \\
\hline
\end{tabular}




\begin{tabular}{|l|l|}
\hline Jaime Fonseca & Álgebra e Cálculo Numérico \\
\hline João Eustáquio de Melo & $\begin{array}{l}\text { Fundamentos de Matemática Elementar e Matemática } \\
\text { Aplicada }\end{array}$ \\
\hline Maria dos Reis & Didática e Psicologia da Educação \\
\hline Elza Rodrigues Pereira & Cálculo Diferencial e Integral e Cálculo Numérico \\
\hline Teresinha de Deus & $\begin{array}{l}\text { Fonseca Princípios e Métodos de Adm Escolar, } \\
\text { Elementos da Adm Escolar e Fundamentos de } \\
\text { Ensino de } 2^{\circ} \text { Grau }\end{array}$ \\
\hline José Gontijo & Psicologia da Educação e História da Educação \\
\hline José Viçoso Rodrigues & Estudos de Problemas Brasileiros \\
\hline Antônio de Pádua Teixeira & Educação Física \\
\hline Francisco de Assis Lana & Geometria Analítica e Prática de Ensino \\
\hline
\end{tabular}

Fonte: Boaventura [3] (2008, p 75).

Ao compararmos os Quadros 1 e 2, percebemos que apenas o nome de seis professores que constavam nos documentos iniciais para lecionar no curso de Matemática configurou na lista de aprovação. Isso nos leva a refletir que as indicações iniciais da listagem dos professores não tinham os documentos necessários para lecionar, contudo aparece uma leva de outros professores com habilitação. Na época, era bastante comum professores lecionarem em diferentes cursos, principalmente, pela escassez de pessoas formadas e como na FAFIPA existiam outros cursos de ensino superior esses professores poderiam ser aproveitados em diferentes cursos (MARIN [21], 2019).

Por meio da comparação dos quadros anteriores, nos chama a atenção sobre a dificuldade que se enfrentava à época para ter um quadro de professores para lecionar de tal forma que satisfizesse os critérios do CNE. Em Marin [21] (2019), percebemos que essa dificuldade não é algo particular e que tenha acontecido apenas em Patos de Minas. Em seu estudo, percebemos que isso aconteceu nos primeiros cursos de formação de professores de Matemática no Triângulo Mineiro. Para fazer um paralelo, o primeiro curso de Matemática criado no Triângulo foi em Uberlândia, no ano de 1968. Agora, se olharmos em termos de Brasil, isso aconteceu em outras regiões, como no estado de São Paulo (MARTINS-SALANDIM [22], 2012), Tocantins (CURY [9], 2011) e Rio Grande do Norte (MORAIS [23], 2017), isso para citar alguns casos.

Um outro aspecto que nos suscitou interesse foi ao encontrar na Revista Documenta $n^{\circ}$ 223 [15], ano de 1974, os cursos de Licenciatura em Ciências Biológicas e de Matemática serem convertidos em Licenciatura Curta, sendo autorizados pelo decreto $\mathrm{n}^{\circ} 76.854$ no dia 17 de dezembro de 1975.

Ao buscar um melhor entendimento sobre esse decreto, nos apoiamos em Marin [21] 
Vestígios da criação do primeiro curso de formação de professores...

(2019) e identificamos que se tratava da Resolução CFE 30/1974 [6] a qual obrigava todos os cursos de Licenciatura migrarem para os cursos de Licenciatura Curta.

No ano de 1975, entra em vigor a Resolução do CFE 37/1975 [7], de 26 de março. Ela tornava obrigatória a formação de professores, estabelecida pela Resolução CFE 30/1974 [6]. Em outras palavras, essa nova resolução impõe a conversão de todos os cursos existentes de formação de professores como complementação em habilitações para o professor poder lecionar no $2^{\circ}$ grau e estipula que isso se cumpra até o primeiro semestre letivo de 1978, como podemos observar no Art. $1^{\circ}$ da referida resolução.

Art. $1^{\circ} \mathrm{O}$ curso de licenciatura em Ciências, a que se refere a Resolução ${ }^{\circ}$
30/74, será implantado progressivamente e, a partir do ano letivo de 1978 ,
tornar-se-á obrigatório como licenciatura única da área científica, com habi-
litação geral em Ciências, para o ensino da respectiva área de estudo, predomi-
nante na escola de $1^{\circ}$ grau, e habilitações específicas em Matemática, Física,
Química e Biologia, para o ensino das correspondentes disciplinas, predomi-
nantes na escola de $2^{\circ}$ grau. Parágrafo único. No curso único de Ciências
disciplinado pela Resolução no $30 / 74$ deverão converter-se, no prazo estabele-
cido por este artigo, as anteriores licenciaturas em Ciências (polivalente), Ma-
temática, Física, Química e Ciências Biológicas reguladas pelas Resoluções
oriundas dos Pareceres n $n^{\circ} 295 / 62,296 / 62,81 / 65$ e $107 / 69$ (CFE 37 [7], 1975,
p. 128).

No caso da FAFIPA, no curso que estamos estudando, a sua conversão foi reconhecida, apenas em 7 de maio 1979. Este curso passou a ser de Ciências, Licenciatura de $1^{\circ}$ grau e Licenciatura plena, com habilitação em Matemática e em Biologia, entretanto não nos aprofundamos nisso, uma vez que nossos interesses estavam fixos na criação do curso.

Esses foram alguns indícios que nos mostram claramente um movimento acerca da criação do curso de formação de professores de Matemática em Patos de Minas, sendo esse o primeiro na região do Alto Paranaíba.

\section{Considerações Finais}

Apresentamos nessa trama resultados de um estudo que tem como objetivo entender como se deu a criação do primeiro curso de formação de professores de Matemática, na região do Alto Paranaíba, usando como fonte principal a Revista Documenta, entretanto, foi possível estabelecer um diálogo com outras fontes às quais tivemos acesso.

Esses resultados, mesmo que incipientes, nos instigam ao delineamento mais detalhado da formação dos professores nessa região. Identificamos que este estudo tem potencialidades de aprofundamento e outras questões para entendermos, como: qual era a formação desses primeiros professores? Onde esses professores se formaram? Que outros cursos de formação de professores de Matemática existiram no Alto Paranaíba? Qual foi 
a influência da Igreja Católica na criação do curso? Com a criação do curso a demanda de professores foi suficiente para abastecer os cursos de educação básica?

Tais questões nos mostram que os próximos passos podem estar na busca de depoentes que vivenciaram esse período de desenvolvimento da difusão cultural, educacional e econômica não apenas na cidade de Patos de Minas mas também, no Alto Paranaíba, se torna viável e imprescindível, e para isso apontamos a História Oral como uma metodologia capaz de nos conduzir nesses entendimentos.

Por fim, destacamos que a expectativa desse estudo está em contribuir com os pesquisadores que têm interesse na História da Educação Matemática, na história da constituição da formação do professor de Matemática nessa região de inquérito, no estudo do currículo dos cursos da época e com a linha/projeto Mapeamento da Formação de Professores de Matemática no Brasil.

\section{Referências}

[1] ALBUQUERQUE JÚNIOR, D. M. História: a arte de inventar o passado - Ensaios de teoria da história. 1. ed. Bauru: EDUSC, 20011.

[2] BARALDI, I. M. Grupo de Pesquisa História Oral e Educação Matemática: dos estudos sobre História da Educação Matemática (Inclusiva). Revista de História da Educação Matemática - Histemat, ano 4, n.3, p.93-103, 2018.

[3] BOAVENTURA, R. M. A gênese e a consolidação do Centro Universitário de Patos de Minas/MG - UNIPAM (1968-1975). 2008. Dissertação (Mestrado em Educação) - Centro Universitário do Triângulo, Uberlândia/MG, 2008.

[4] BRASIL. Ministério da Educação. Governo Federal. Decreto n ${ }^{\circ}$ 50.163, de 28 de janeiro de 1961. 1961. Disponível em http://www2.camara.leg.br/ legin/fed/decret/1960-1969/decreto-50163-28-janeiro1961-389980-publicacaooriginal-1-pe.html. Acesso em: 26 set. 2019.

[5] BRASIL. Lei no 4024, de 20 de dezembro de 1961. Fixa as diretrizes e bases da Educação Nacional. LDB. Brasília, Disponível em: http: / / www . planalto. gov.br/ccivil_03/Leis/L4024.htm. Acesso em: 25 set. 2019.

[6] CONSELHO FEDERAL DE EDUCAÇÃO (CFE). (1974). Resolução no 30, de 11 de julho de 1974. Fixa os mínimos de conteúdo e duração a observar na organização do curso de licenciatura em Ciências. Documenta, Brasília, (164): 509-11. 
[7] . (1975). Resolução no 37, de 26 de março de 1975. Dispõe sobre a implantação progressiva do curso de licenciatura em Ciências, a que se refere a Resolução $n^{0}$ 30/74. Alterado pela R. 05/1978. Diário Oficial, Brasília, 26 de março de 1975. Seção 1, pt. 1, p. 3.635.

[8] (1978). Resolução ${ }^{\circ}$ 05, de 16 de junho de 1978. Adia o prazo estabelecido pela Resolução ${ }^{\circ}$ 37/75 e para a obrigatoriedade da conversão em Ciências nos moldes da Resolução no 30/74. Documenta, Brasília, (211): 20.

[9] CURY, F. G. Uma história da formação de professores de Matemática e das Instituições formadoras do estado do Tocantins. 2011. Tese (Doutorado em Educação Matemática) - Instituto de Geociências e Ciências Exatas, Universidade Estadual Paulista "Júlio de Mesquita Filho", Rio Claro/SP, 2011.

[10] DOCUMENTA. Rio de Janeiro: Conselho Federal de Educação. 1962 até 1979.

[11] . Rio de Janeiro: Conselho Federal de Educação. v.10, 1962. Rio de Janeiro: Conselho Federal de Educação. v.78, 1971.

[13] Rio de Janeiro: Conselho Federal de Educação. v.79, 1971.

[14] Rio de Janeiro: Conselho Federal de Educação. v.135, 1972. Rio de Janeiro: Conselho Federal de Educação. v.223, 1974.

[16] GARNICA, A. V. M. Grupo de Pesquisa História Oral e Educação Matemática: mapeamento da formação e atuação de professores que ensinam/ensinaram matemática no Brasil. Revista de História da Educação Matemática - Histemat, ano 4, n.3, p.68-92, 2018.

[17] GARNICA, A. V. M.; SOUZA, L. A. Elementos de História e de Educação Matemática. São Paulo: Cultura Acadêmica, Unesp, 2012.

[18] GHOEM - GRUPO HISTÓRIA ORAL E EDUCAÇÃO MATEMÁTICA. Sobre o Ghoem. Bauru, 2015. Disponível em: http: / / www2. fc. unesp.br/ghoem/. Acesso em: mai. 2019.

[19] GOMES, L. N. O que nos conta a Revista Documenta: sobre cursos que formavam professores de Matemática no Brasil (1962 a 1979). 2019. Dissertação (Mestrado) Pós-Graduação em Educação para a Ciência, Universidade Estadual Paulista "Júlio de Mesquita Filho", Bauru/SP, 2019. 
[20] JENKINS, K. A História Repensada. São Paulo: Contexto, 2005.

[21] MARIN, D. Uma história da criação dos primeiros cursos de formação de professores (de Matemática) no Triângulo Mineiro- Minas Gerais. 2019. Tese (Doutorado em Educação para Ciência) - Universidade Estadual Paulista "Júlio de Mesquita Filho", Rio Claro, SP, 2019.

[22] MARTINS-SALANDIM, M. E. A interiorização dos cursos de Matemática no estado de São Paulo: um exame da década de 1960. 2012. Tese (Doutorado em Educação Matemática) - Instituto de Geociências e Ciências Exatas, Universidade Estadual Paulista “Júlio de Mesquita Filho", Rio Claro/SP, 2012.

[23] MORAIS, M. B. Se um viajante... percursos e histórias sobre a formação de professores de Matemática no Rio Grande do Norte. 2017. Tese (Doutorado em Educação Matemática) - Instituto de Geociências e Ciências Exatas, Universidade Estadual Paulista "Júlio de Mesquita Filho", Rio Claro/SP, 2017.

[24] PATOS de Minas. Wikipedia. Disponível em: https://pt.wikipedia.org/ wiki/PatosdeMinas. Acesso em: 12 fev. 2020.

[25] QUELUZ, J. A. O primeiro curso de formação de professores de Matemática no Alto Paranaíba, Minas Gerais: um olhar a partir da Revista Documenta. 2019. 39 f. Trabalho de Conclusão de Curso (Graduação em Matemática) - Universidade Federal de Uberlândia, Uberlândia, 2020.

[26] ROTHEN, J. C. O Conselho Federal de Educação nos bastidores da Reforma Universitária de 1968. In III Congresso Brasileiro de História da Educação Curitiba, PR. Anais ... Curitiba, PR: PUCPR, 2004.

Submetido em 29 fev. 2020

Aceito em 28 abr. 2020 